\title{
Nonisothermal desorption at nucleate boiling in a layer of aqueous salt solution
}

\author{
Vladimir Morozov ${ }^{*}$, Dmitriy Elistratov \\ Institute of Thermophysics Siberian Branch, Russian Academy of Sciences, Lavrentiev \\ Ave. 1, Novosibirsk 630090, Russia
}

\begin{abstract}
This paper presents the results of experimental studies of nonisothermal desorption at nucleate boiling of layers of aqueous salt solutions of $\mathrm{LiBr}$ and $\mathrm{CaCl}_{2}$. The height of the layers is $2.8 \mathrm{~mm}$. The wall temperature is $120{ }^{\circ} \mathrm{C}$. The drop in the temperature of the interfacial surface $\left(T_{\mathrm{s}}\right)$ for salt solutions and distillate is associated with low thermal conductivity of the metal wall (titanium) and intense heat flow at nucleate boiling. A heat balance for a free liquid interface has been worked out. In 75 seconds after the beginning of evaporation, the heat flux for aqueous becomes quasi-permanent, and for aqueous salt solutions of $\mathrm{CaCl}_{2}$ and $\mathrm{LiBr}$, the heat flux continuously decreases with time. This is due to the increase in the salt concentration in the solution and the drop in the equilibrium partial pressure of the vapor.
\end{abstract}

\section{Introduction}

The processes of boiling and evaporation are widely used in practice for cooling microelectronics and are often observed in medicine, biology and nature. Desorption and absorption of aqueous salt solutions of $\mathrm{LiBr}, \mathrm{CaCl}_{2}$ are used in desorbers and absorbers of heat pumps. Phase transformations in heat pumps depend on the heat flux $[1,2]$. The nonisothermal desorption of aqueous salt solutions at a temperature below boiling was studied in [3-5]. Evaporation of pure liquids differs significantly from solutions [6-9]. An increase in the salt concentration in the liquid layer leads to a significant decrease in the desorption rate. The spray cooling is widely used in heat exchangers to improve the efficiency of heat transfer [10-11]. The formation of vapor flow and small droplets during combustion of gas hydrates result in a decrease in the combustion temperature and in the efficiency of the technology of gas hydrates combustion [12-17]. At liquid gas boiling, a multicomponent mixture is formed (vapor-liquid droplets-crystal hydrates) [18]. Experimental studies of heat and mass transfer during evaporation of a thin layer of aqueous salt solution was discussed in [19-21]. The structured wall intensifies the heat transfer [22]. There are different modes of liquid boiling on a heated horizontal surface: the nucleate boiling regime [23-25] and the film boiling regime [26]. The nucleate boiling of fluid with high superheating depends on the physicochemical and geometric properties of the solid wall. At boiling in the layer, the layer height, the evaporation rate and the

* Corresponding author: morozov.vova.88@mail.ru 
interfacial temperature change over time. Bubbles, at vapor boiling in a layer of liquid, mix it, causing circulation, which increases convection [27]. For nucleate boiling it is important to know the number of active boiling points [27]. In the boiling crisis, the resulting vapor layer, separating the liquid layer from the wall, leads to a several order decrease in the heat transfer coefficient; as a result overheating and destruction of the walls occur.

To date, there are few experimental studies of nucleate boiling in horizontal thin layers. The purpose of this work is an experimental study of nonisothermal desorption during bubble boiling of thin layers of water solutions of $\mathrm{LiBr}$ and $\mathrm{CaCl}_{2}$ salts.

\section{Experimental data}

The experiments were carried out on a horizontal heated titanium wall (Fig. 1). The ambient temperature was $25^{\circ} \mathrm{C}$, and the pressure was $1 \mathrm{~atm}$. The diameter of the working surface was $65 \mathrm{~mm}$, and the height was $50 \mathrm{~mm}$. The height of the layer was $2.8 \mathrm{~mm}$. The wall temperature was $120{ }^{\circ} \mathrm{C}$. The initial concentration of aqueous solutions of $\mathrm{LiBr}$ and $\mathrm{CaCl}_{2}$ was $10 \%$ and was determined by standard densitometers. The thermal field of the layer $\left(T_{\mathrm{s}}\right)$ was measured by a thermal imager (NEC R500) (5). The temperature of the heated wall $\left(T_{\mathrm{w}}\right)$ was determined by means of thermocouples (3) located near the wall. The maximum error in measuring $T_{\mathrm{w}}$ did not exceed $1-2{ }^{\circ} \mathrm{C}$. The distillate layer and aqueous salt solutions of the $\mathrm{LiBr}$ and $\mathrm{CaCl}_{2}$ were formed on the surface using a Finnpipette Novus volumetric dispenser. The experiments were carried out until the boiling stopped.

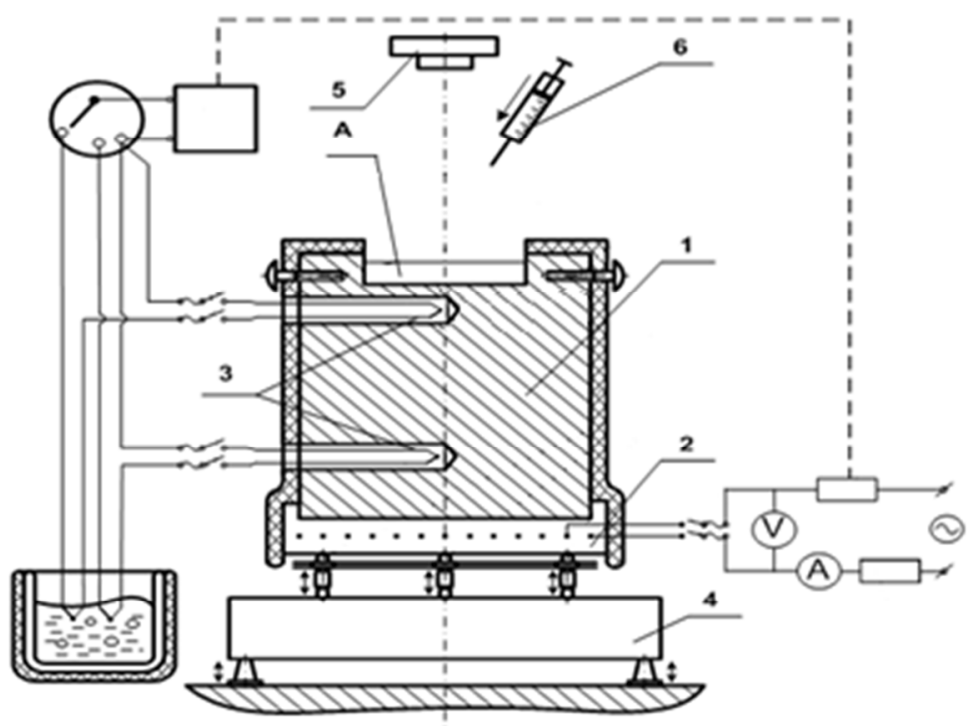

Fig. 1. Scheme of experimental setup: A - working heating surface; 1 - titanium cylinder; 2 - electric heater; 3 - thermocouples; 4 - analytical balance; 5 - video camera, thermal imager; 6 - dispenser.

The drop in the temperature of the interfacial surface $\left(T_{\mathrm{s}}\right)$ (Fig. 2) for solutions of salts and distillate is associated with low thermal conductivity of the metal wall (titanium), thermal inertia and high heat flux during nucleate boiling. The non-uniformity of temperature is associated with the destruction of bubbles and convection in the layer. 


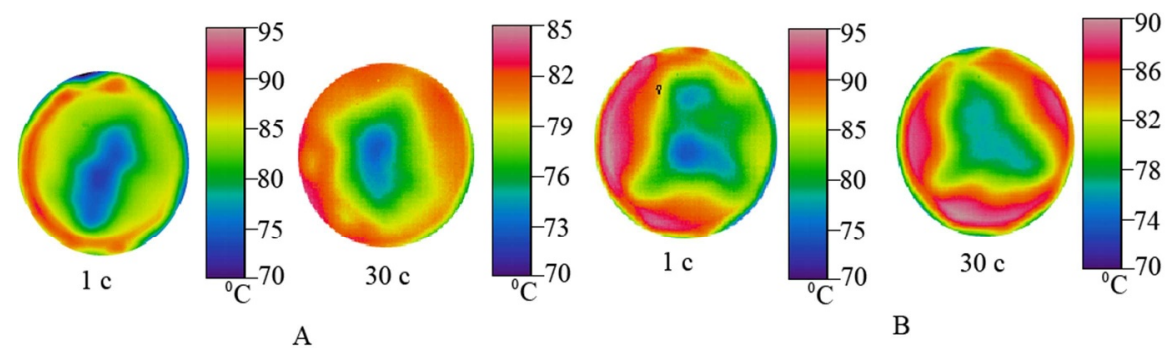

Fig. 2. Thermal image: A) $\mathrm{H}_{2} \mathrm{O}$; B) $\mathrm{H}_{2} \mathrm{O} / \mathrm{CaCl}_{2}$.

Fig. 3 shows the experimental data on the change in the total heat flux $\left(q_{\Sigma}\right)$ over time $(t)$. The heat balance equation for the free surface of a liquid has the form (1).

$$
q_{\Sigma}=q_{\mathrm{w}}=q_{h}+q_{\mathrm{e}}+q_{\mathrm{c}}+q_{\mathrm{r}}
$$

were $q_{\mathrm{w}}=\lambda_{w}(d T / d y)_{\mathrm{y}=0}$ is the heat flux density of the wall, $q_{\mathrm{h}}=c_{\mathrm{p}} d\left(m \Delta T_{1}\right) / d t \cdot(1 / F)$ is the heat flux due the liquid heating, $q_{\mathrm{e}}=r \mathrm{j} / F$ is the heat flux due to evaporation, $q_{\mathrm{c}}=\alpha_{g}\left(T_{\mathrm{s}}-T_{0}\right)$ is the heat flux due to gas convection, $q_{\mathrm{r}}=\varepsilon \sigma\left(T_{\mathrm{s}}^{4}-T_{0}^{4}\right)$ is the heat flux due to radiation, $\lambda_{\mathrm{w}}$ is the thermal conductivity of the titanium alloy, $y$ is the coordinate transverse to the metal wall ( $y=0$ corresponds to the surface of the wall), $c_{\mathrm{p}}$ is the heat capacity of liquid, $\mathrm{r}$ is the latent heat of desorption for the aqueous salt solution, $j$ is the evaporation rate $(j=\Delta m /(\Delta t F)), m$ is the change in the layer mass, $t$ is the time, $r$ is the latent heat of vaporization, $F$ is the area of interface of the layers, $t$ is the time, $T_{1}$ is the average temperature throughout the layers volume, $\varepsilon$ is the coefficient of thermal radiation for the liquid, $\sigma$ is the Stefan-Boltzmann constant, and $T_{0}$ is the ambient temperature. The difference $\Delta=\left(q_{\mathrm{w}}-q_{\Sigma}\right) 100 \% / q_{\mathrm{w}}$ did not exceed $5-8 \%$. The impact of gas convection and heat radiation is negligible compared to the evaporation heat.

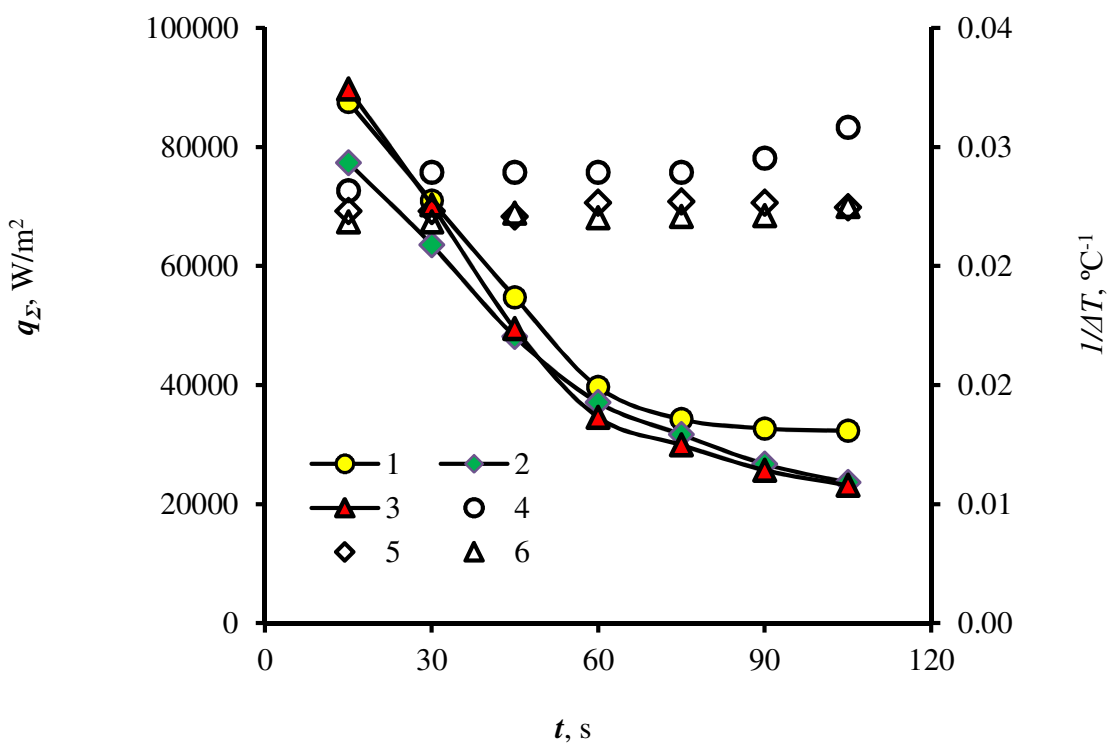

Fig. 3. Total heat flux $q_{\Sigma}\left(\mathrm{W} / \mathrm{m}^{2}\right)$ depending on time: $1-\mathrm{H}_{2} \mathrm{O} ; 2-\mathrm{H}_{2} \mathrm{O} / \mathrm{LiBr} ; 3-\mathrm{H}_{2} \mathrm{O} / \mathrm{CaCl}_{2}$ and $1 / \Delta T=1 /\left(T_{\mathrm{w}}-T_{\mathrm{s}}\right): 4-\mathrm{H}_{2} \mathrm{O} ; 5-\mathrm{H}_{2} \mathrm{O} / \mathrm{LiBr} ; 6-\mathrm{H}_{2} \mathrm{O} / \mathrm{CaCl}_{2}$.

After 75 seconds of the beginning of evaporation, the heat flux for water becomes quasi-permanent; and for aqueous salt solutions of $\mathrm{CaCl}_{2}$ and $\mathrm{LiBr}$ the heat flux $\left(q_{\Sigma}\right)$ continuously decreases with time (Fig. 3). The heat flux for aqueous salt solutions 
decreases due to an increase in salt concentration, low thermal conductivity of the metal wall and drop of the evaporation rate.

\section{Conclusions}

The nonisothermal desorption of layers of aqueous salt solutions of $\mathrm{H}_{2} \mathrm{O} / \mathrm{LiBr}$ and $\mathrm{H}_{2} \mathrm{O} / \mathrm{CaCl}_{2}$ with intense nucleate boiling has been studied experimentally. Methods for determining the heat flux are important for correct modeling of non-stationary regimes in: heat pumps, chemical technologies for cellulose production and desalination technologies.

Experiments were carried out at the Kutateladze Institute of Thermophysics of SBRAS and were financially supported by grants of the Russian Science Foundation (Project No. 15-19-10025).

\section{References}

1. V.E. Nakoryakov et. al., Int. J. of Heat and Mass Transfer 55, 6514 (2012)

2. V.E. Nakoryakov et. al., Int. J. of Heat and Mass Transfer 54, 4485 (2011)

3. V E Nakoryakov et.al., J. Engineering Thermophysics 23, 257 (2014)

4. V.E. Nakoryakov et. al., J. of Engineering Thermophysics 20, 338 (2011)

5. S.Y. Misyura, Chem. Eng. Research and Design 126, 153 (2017)

6. R.S. Volkov et. al., Exp. Therm. Fluid Sci. 99, 59 (2018)

7. G.V. Kuznetsov et. al., Int. J. Heat Mass Transfer 126, 161 (2018)

8. G.V. Kuznetsov et. al., J. of Engineering Thermophysics 89, 317 (2016)

9. P.A. Strizhak et. all., Int. J. of Therm. Sci. 134, 421 (2018)

10. G.V. Kuznetsov et. al., Exp. Therm. Fluid Sci. 81, 256 (2017)

11. G.V. Kuznetsov et. al., Appl. Therm. Eng. 131, 340 (2018)

12. M.E. Semenov et. all., Journal of Thermal Analysis and Calorimetry 119, 757 (2015)

13. S.Y. Misyura, V.E. Nakoryakov, Energy and Fuels 27, 7089 (2013)

14. V.E. Nakoryakov et. al., J. of Engineering Thermophysics 22, 169 (2013)

15. V.E. Nakoryakov et. al., J. of Engineering Thermophysics 22, 87 (2013)

16. S.Y. Misyura, I.G. Donskoy, Chem. Eng. Sci. 148, 65 (2016)

17. S.Y. Misyura, Energy 103, 430 (2016)

18. A.A. Chernov et al., Scientific Reports 7, 40809 (2017)

19. S.Y. Misyura, Scientific Reports 8, 11521 (2018)

20. S.Y. Misyura, Appl. Therm. Eng. 139, 203 (2018)

21. V.P. Lebedev et. al., Fluid dynamics 28, 624 (1993)

22. S.Y. Misyura, Appl. Surf. Sci. 414, 188 (2017)

23. S.Y. Misyura, Exp. Therm. Fluid Sci. 75, 43 (2016)

24. V.E. Nakoryakov et. al., J. of Engineering Thermophysics 25, 24 (2016)

25. V.E. Nakoryakov et. al., Doklady Physics 59, 441 (2014)

26. S.Y. Misyura, Exp. Therm. Fluid Sci. 84, 190 (2017)

27. S.Y. Misyura, Scientific Reports 7, 14759 (2017) 